\title{
Heritability of Schneider's first-rank symptoms
}

\author{
ALASTAIR G. CARDNO, PAK C. SHAM, ANNE E. FARMER, ROBIN M. MURRAY \\ and PETER McGUFFIN
}

\begin{abstract}
Background Schneider's first-rank symptoms are given particular weight when making a diagnosis of schizophrenia, but the nuclear syndrome, characterised by one or more first-rank symptoms, has been found previously to have no heritability.
\end{abstract}

Aims To estimate the heritability of the nuclear syndrome.

Method A total of 224 twin pairs (106 monozygotic, 118 same-gender dizygotic) were ascertained from the Maudsley Twin Register in London via probands with any psychosis. Lifetime-ever first-rank symptoms were rated using the OPCRIT checklist. Probandwise concordance rates were calculated for the nuclear syndrome and a heritability estimate was derived from biometric model fitting.

Results Probandwise concordance rates were $13 / 49$ (26.5\%) for monozygotic and 0/45 to 2/46 (0.0-4.3\%) for dizygotic pairs. The heritability estimate for the bestfitting model was 71\% (95\% Cl 57-82).

Conclusions These results indicate that the nuclear syndrome shows substantial heritability, although this is slightly lower than that for schizophrenia as defined by the DSM and ICD systems.

Declaration of interest None.

Funding from the National Institute of Mental Health and the Stanley

Foundation.
First-rank symptoms (Schneider, 1959) are given particular weight for making a diagnosis of schizophrenia in commonly used classification systems such as ICD-10 (World Health Organization, 1992) and DSM-IV (American Psychiatric Association, 1994). However, the value of first-rank symptoms has been questioned (Crichton, 1996), partly on the basis of a twin study (McGuffin et al, 1984) that found no heritability for the nuclear syndrome of schizophrenia, defined by the presence of one or more first-rank symptoms. In that study, McGuffin et al (1984) re-analysed data from Gottesman \& Shields' (1972) schizophrenia twin series derived from the Maudsley Hospital Twin Register in London. The probandwise concordance rate was $2 / 9(22.2 \%)$ for monozygotic (MZ) twins and $2 / 4(50.0 \%)$ for dizygotic (DZ) twins, suggesting no genetic effect. However, the sample size was small and was ascertained via probands with clinical schizophrenia, and first-rank symptoms also occur frequently in other psychoses (Peralta \& Cuesta, 1999).

The aim of the current study was to determine probandwise concordance rates and to make a heritability estimate for a syndrome characterised by the presence of one or more first-rank symptoms in a systematically ascertained sample of twins with any psychosis. The sample came from the Maudsley Hospital Twin Register and therefore included that of Gottesman \& Shields (1972) as a subsample.

\section{METHOD}

\section{Subjects}

The sample has been described in detail elsewhere (Cardno et al, 1999b). Briefly, probands were ascertained from the Maudsley Twin Register in London, as patients of multiple birth who had attended any facility of the Maudsley and Bethlem Royal Hospitals between 1948 and 1993, who had a same-gender co-twin surviving to adulthood, and who had suffered psychotic symptomatology (Sartorius et al, 1986) or an episode of mania or hypomania defined according to research diagnostic criteria (RDC; Spitzer et al, 1978) at some time in their lives. Probands were excluded if they had a primary diagnosis of dementia or if psychotic symptoms occurred only during acute organic states. The 114 twins studied by Gottesman \& Shields (1972) were included in the current sample. Of these, 107 were followed up for a further 25 years or until death, through information from hospital case notes and general practitioners. Of these twins, 31 were interviewed further.

Zygosity determination was carried out blind to research diagnosis and was based on all the available information, including analysis of genetic markers in $42 \%$ of pairs. Agreement between zygosity determination by genetic markers and by resemblance information was $95 \%$.

The sample comprised 224 probandwise twin pairs (120 male and 104 female), from which 28 probands $(12.5 \%)$ were doubly ascertained after checking for independence of ascertainment. A total of $197(87.9 \%)$ pairs were White. The mean age of co-twins at last follow-up was 46.5 years (s.d.=15.4). There was no substantial ascertainment bias for zygosity (106 MZ and 118 same-gender DZ pairs), but the sample may have contained more severe cases than if we had ascertained via a population-based sample (Cardno et al, 1999b).

\section{Clinical assessment}

This was based on all available clinical information, which included a research interview (Gottesman \& Shields' (1972) cued-questions interview and/or the Schedule for Affective Disorders and Schizophrenia Lifetime version (SADS-L; Spitzer \& Endicott, 1978)) in $72.8 \%$ of probands and $59.4 \%$ of co-twins. Interviewed twins gave informed consent to be studied. Clinical ratings were made by separate assessors for each member of twin pairs concordant for psychosis.

For each subject, first-rank symptoms were rated on the OPCRIT checklist (McGuffin et al, 1991), blind to the symptoms of the other twin, under the symptom categories of thought echo, third-person auditory hallucinations, running commentary voices, delusions of passivity, primary delusional perception, thought insertion, 
thought withdrawal and thought broadcast. Interrater reliability for rating the presence/ absence of first-rank symptoms was assessed on 30 cases. The mean kappa score between raters was 0.66

Of the total, 94 probands were rated as having one or more first-rank symptoms: $57(60.6 \%)$ were male and $37(39.4 \%)$ were female. Probands had the following distribution of RDC main-lifetime diagnoses: schizophrenia, 67 (71.3\%); schizoaffective disorder, 16 (17.0\%); bipolar I disorder, 5 (5.3\%); depressive psychosis, 3 $(3.2 \%)$; and unspecified functional psychosis, $3(3.2 \%)$.

In the whole sample of 224 probands, the frequency of probands having first-rank symptoms in each RDC main-lifetime diagnostic category was as follows: schizophrenia, 67/106 (63.2\%); schizoaffective disorder, 16/33 (48.5\%); bipolar I disorder, $5 / 27$ (18.5\%); bipolar II disorder, 0/4 (0.0\%); depressive psychosis, $3 / 20$ (15.0\%); unspecified functional psychosis, 3/32 $(9.4 \%)$; and other, $0 / 2(0.0 \%)$.

\section{Statistical analysis}

Probandwise concordance rates for $\mathrm{MZ}$ and DZ pairs were calculated for a nuclear syndrome characterised by the presence of one or more first-rank symptoms. The population lifetime morbid risk for the nuclear syndrome was estimated as described previously (Cardno et al, $1999 b$ ), based on data from the Camberwell Case Register and the twin series of Gottesman \& Shields (1972), and was $0.73 \%(95 \%$ CI $0.57-0.99)$. In case of any inaccuracy in the morbid risk estimate, the analysis was performed for the actual estimate $(0.73 \%)$ and also for the upper extreme of the $95 \%$ confidence interval $(0.99 \%)$ (because heritability estimates tend to decrease as morbid risk estimates increase).

The Mx program (Neale, 1999) was used to calculate correlations in liability for the nuclear syndrome. These are tetrachoric correlations, based on a liabilitythreshold model (Falconer, 1965), that make use of concordance rates and estimates of morbid risk. The Mx program was used also for biometric model fitting. Five models were fitted, differing in the parameters that were assumed to contribute variance in liability to the nuclear syndrome: individual specific environmental variance only (E model); common and specific environmental variance (CE model); additive genetic and specific environmental variance (AE model); additive genetic, common and specific environmental variance (ACE model); and additive genetic, genetic dominance and specific environmental variance (ADE model). Nested models were compared using the $\chi^{2}$ difference test. Where there was no significant difference the best-fitting model was determined on grounds of parsimony, those models with fewer parameters being preferred.

\section{RESULTS}

The probandwise concordance rate for the nuclear syndrome was $13 / 49(26.5 \%)$ for MZ twins and 0/45 (0.0\%) for DZ twins. For the subsample investigated previously by McGuffin et al (1984) the concordance rates were $3 / 14(21.4 \%)$ for $\mathrm{MZ}$ twins and $0 / 12(0.0 \%)$ for DZ twins (compared with $2 / 9(22.2 \%)$ and $2 / 4(50.0 \%)$, respectively, in that study). Thus, the further follow-up of this subsample and increased focus on first-rank symptoms in the followup SADS-L interviews and case-note reviews resulted in more of the previously studied twins being rated as having one or more first-rank symptoms (26 probands in the current study compared with 13 in the previous study). The $\mathrm{MZ}$ concordance rate remained very similar $21.4 \% v .22 .2 \%$ ) but the DZ concordance rate was notably lower in the current study $(0.0 \% v .50 .0 \%)$. The two concordant DZ pairs in the study of McGuffin et al (1984) were derived from one doubly ascertained pair. In Gottesman \& Shields' (1972) published vignette of this pair (DZ 7), twin A is described as having delusions of gender changes, as saying "the devil set me up in the corner" and that she was experimented on by evolutionary scientists. Twin B is described as thinking she could feel her face changing and having "somatic delusions; arm twisted... changing into a man" (although the account of her history used for the current study does not mention her arm being twisted). Even if these twins are regarded as having firstrank symptoms, the $\mathrm{DZ}$ concordance rate $(2 / 46,4.3 \%)$ remains considerably lower than the MZ concordance rate, and the correlations in liability have non-overlapping 95\% confidence intervals: $\mathrm{MZ}$ correlation 0.72 (0.58-0.83); DZ correlation 0.29 $(0.00-0.53)$.

The results of biometric model fitting for the nuclear syndrome, assuming a DZ concordance rate of $2 / 46$, are shown in Table 1. The models of individual specific environmental factors explaining all of the variance in liability (E) and of common plus specific environmental variance (CE) could be rejected by the $\chi^{2}$ difference test compared with the models of additive genetic, common environmental and specific environmental variance (ACE) and additive genetic, genetic dominance and specific environmental variance (ADE). However, the model of additive genetic and specific environmental variance (AE) could not be rejected compared with the ACE and ADE models, and on grounds of parsimony was the best-fitting model. The ACE and ADE models could not be rejected formally; however, under the ACE model the additive genetic variance $\left(a^{2}\right)$ remained the same $(0.72$ or $71 \%)$ and common environmental variance $\left(c^{2}\right)$ was estimated as zero. Also, under the ADE model $a^{2}$ was 0.43 and variance due to genetic dominance $\left(d^{2}\right)$ was 0.29 , so the total genetic variance remained similar at 0.72 or $72 \%$.

Similar results were obtained when the morbid risk estimate for the nuclear syndrome was increased to $0.99 \%$ (the upper extreme of the $95 \% \mathrm{CI}$ for the morbid

Table I Results of biometric model fitting for the nuclear syndrome

Fit of models in $\chi^{2}$ units

\begin{tabular}{|c|c|c|c|c|c|c|}
\hline \multirow[b]{2}{*}{$\begin{array}{c}E \\
\text { (d.f. }=2)\end{array}$} & \multicolumn{4}{|c|}{ Fit of models in $\chi^{2}$ units } & \multicolumn{2}{|c|}{$\begin{array}{l}\text { Parameter estimates of best-fitting model } \\
\qquad(95 \% \text { confidence interval) }\end{array}$} \\
\hline & $\begin{array}{c}\mathrm{CE} \\
\text { (d.f. }=I)\end{array}$ & $\begin{array}{c}A E \\
(\text { d.f. }=I)\end{array}$ & $\begin{array}{c}\mathrm{ACE} \\
(\text { d.f. }=0)\end{array}$ & $\begin{array}{c}\mathrm{ADE} \\
(\mathrm{d} . f .=0)\end{array}$ & $a^{2}$ & $e^{2}$ \\
\hline 75.54 & 9.72 & $0.28^{1}$ & 0.28 & 0.00 & $0.71(0.57-0.82)$ & $0.29(0.18-0.43)$ \\
\hline
\end{tabular}

$E$, model with specific environmental variance in liability only; $C E$, model with common and specific environmenta variance; $A E$, model with additive genetic and specific environmental variance; $A C E$, model with additive genetic, common and specific environmental variance; $A D E$, model with additive genetic, genetic dominance and specific environmental variance; $a^{2}$, additive genetic variance in liability (heritability); $\mathrm{e}^{2}$, specific environmental variance in liability.

I. Best-fitting model. 
risk). The $\mathrm{AE}$ model was best fitting $\left(\chi^{2}=0.51\right.$, d.f. $\left.=1, P=0.48\right)$, with $a^{2}=0.69$ (95\% CI $0.54-0.81)$ and $e^{2}=0.31(95 \%$ CI 0.19-0.46). The results also remained similar, assuming a DZ concordance of $0 /$ 45 (and a morbid risk of $0.73 \%$ ). The AE model again was best fitting, with $a^{2}=0.69$ (95\% CI $0.54-0.81)$ and $e^{2}=0.31(95 \%$ CI 0.19-0.46); however, in this case the model fitted less well $\left(\chi^{2}=5.55\right.$, d.f. $\left.=1, P=0.02\right)$, probably because of the zero concordance rate for $\mathrm{DZ}$ pairs.

\section{DISCUSSION}

\section{Nuclear syndrome defined by first-rank symptoms is heritable}

The results of this study are compatible with a genetic contribution to variance in liability to the nuclear syndrome, characterised by the presence of one or more first-rank symptoms of schizophrenia. The concordance rates and correlations in liability were greater in $\mathrm{MZ}$ than $\mathrm{DZ}$ twins, and biometric models that did not include a genetic component ( $\mathrm{E}$ and $\mathrm{CE}$ ) could be rejected formally. We conclude that the previous finding of a greater concordance rate in DZ than MZ twins in a subsample of the current sample (McGuffin et al, 1984) probably was an artefact. This was overcome in the current study by increasing the sample size, following up the twins for longer and performing follow-up interviews (SADS-L) and casenote reviews that focused more on firstrank symptoms.

\section{Comparison with other definitions of schizophrenia}

The heritability estimate of $71 \%$ (95\% CI 57-82) is substantial but somewhat lower than heritability estimates based on the same sample for schizophrenia defined according to RDC (82\%, 95\% CI 71-90), DSM-III-R (American Psychiatric Association, 1987) (84\%, 95\% CI 19-92) and ICD-10 (83\%, 95\% CI 7-91) criteria (Cardno et al, 1999b). However, the confidence intervals for all these heritability estimates overlap. Indeed, it can be argued that the true confidence intervals for our estimate of heritability should be even larger because we explored a range of population frequencies without allowing for error, and our interrater agreement, although good with a mean kappa of 0.66 , was not perfect.

\section{CLINICAL IMPLICATIONS}

- This study provides evidence of a genetic contribution to the aetiology of the nuclear syndrome, defined by the presence of one or more first-rank symptoms of schizophrenia.

- The heritability of the nuclear syndrome is approximately $70 \%$.

- The heritability of the nuclear syndrome is slightly lower than that of RDC, DSM-III-R and ICD-10 schizophrenia (although the confidence intervals for each definition of schizophrenia overlap).

\section{LIMITATIONS}

- The sample probably contained more severe cases than if ascertainment had been population-based.

- Shared environmental and genetic dominance effects were not present in the bestfitting model, but could not be excluded formally.

- Although most twins received one or more research interviews, some ratings of first-rank symptoms were based on retrospective assessments of case records.

ALASTAIR G. CARDNO, MRCPsych, Departments of Psychological Medicine and Medical Genetics, University of Wales College of Medicine, Cardiff; PAK C. SHAM, MRCPsych, ANNE E. FARMER, FRCPsych, ROBIN M. MURRAY, FRCPsych, PETER McGUFFIN, FRCPsych, Institute of Psychiatry, London

Correspondence: Professor Peter McGuffin, Director and Professor of Psychiatric Genetics, Social Genetic and Developmental Psychiatry (SGDP) Research Centre, Institute of Psychiatry, Kings College London, De Crespigny Park, London SE5 8AF, UK. Tel: 0207848 087I ; Fax: 0207848 0866; e-mail: p.mcguffin@iop.kcl.ac.uk

(First received 8 May 200I, final revision 10 September 200I, accepted 27 September 200I)

\section{Familial aggregation}

It should be noted that the current study takes a different approach from those that have investigated the familial aggregation of first-rank symptoms in pairs of siblings (Cardno et al, 1998, 1999a; Loftus et al, 1998, 2000) or twins (details available from the author upon request) that are concordant for schizophrenia or other psychoses. These studies generally have found only very modest familial aggregation of first-rank symptoms within pairs of relatives who both have psychosis. In addition, the presence of first-rank symptoms in individuals with schizophrenia or other psychoses has not been found to predict the risk of psychoses in their relatives (Cardno et al, 1997), including co-twins from the current sample (details available from the author upon request). Therefore, first-rank symptoms do not appear to be useful indicators of the level of genetic liability to psychoses in affected individuals. However, as the current study shows, a syndrome defined by the presence or absence of first-rank symptoms (where absence of first-rank symptoms includes individuals unaffected by psychosis) may have substantial heritability. It appears, from a genetic point of view, that first-rank symptoms (and other positive psychotic symptoms) are fairly non-specific epiphenomena of general psychotic processes. If so, other combinations of psychotic symptoms, or individual symptoms, might well also show evidence of heritability.

\section{Implications for molecular genetic studies}

The question remains whether the nuclear syndrome is likely to provide a useful phenotypic definition for molecular genetic studies of schizophrenia. Given that there are other operational definitions of 
schizophrenia that show trends towards higher heritabilities, and that first-rank symptoms do not appear to be markers of particularly high genetic liability to schizophrenia, the answer probably is no.

\section{ACKNOWLEDGEMENTS}

The National Institute of Mental Health (MH44359) and the Stanley Foundation provided grant support that enabled collection of the clinical data. The authors thank Jane Marshall, Bina Coid, Alison Macdonald, Tracy Ribchester, Nadia Davies, Piero Venturi, Lisa Jones, Shôn Lewis, Irving Gottesman and Adrianne Reveley for their work on this study.

\section{REFERENCES}

American Psychiatric Association (1987) Diagnostic and Statistical Manual of Mental Disorders (3rd edn revised) (DSM-III-R). Washington, DC: APA.

- (1994) Diagnostic and Statistical Manual of Mental Disorders (4th edn) (DSM-IV). Washington, DC: APA

\section{Cardno, A. G., Holmans, P. A., Harvey, l., et al (1997)}

Factor-derived subsyndromes of schizophrenia and familial morbid risks. Schizophrenia Research, 23, 23I-238.
_ , Jones, L. A., Murphy, K. C., et al (1998) Sibling pairs with schizophrenia or schizoaffective disorder: associations of subtypes, symptoms and demographic variables. Psychological Medicine, 28, 815-823.

_ , Marshall, E. J., Coid, B., et al (1999a) Heritability estimates for psychotic disorders: the Maudsley twin psychosis series. Archives of General Psychiatry, 56 162-168.

—, Jones, L. A., Murphy, K. C., et al (1999b)

Dimensions of psychosis in affected sibling pairs. Schizophrenia Bulletin, 25, 84I-850.

Crichton, P. (1996) First-rank symptoms or rank-andfile symptoms? British Journal of Psychiatry, 169, 537-540.

Falconer, D. S. (1965) The inheritance of liability to certain diseases, estimated from the incidence among relatives. Annals of Human Genetics, 29, 5I-76.

Gottesman, I. I. \& Shields, J. (1972) Schizophrenia and Genetics: A Twin Vantage Point. New York: Academic Press.

Loftus, J., DeLisi, L. E. \& Crow, T. J. (1998) Familia associations of subsyndromes of psychosis in affected sibling pairs with schizophrenia and schizoaffective disorder. Psychiatry Research, 80, I0I-III.

_, _ \& _ (2000) Factor structure and familiality of first-rank symptoms in sibling pairs with schizophrenia and schizoaffective disorder. British Journal of Psychiatry, 177, 15-19.

McGuffin, P., Farmer, A. E., Gottesman, I. I., et al (1984) Twin concordance for operationally defined schizophrenia: confirmation of familiality and heritability. Archives of General Psychiatry, 4I, 54I-545.

_, _ \& Harvey, I. (1991) A polydiagnostic application of operational criteria in studies of psychotic illness: development and reliability of the OPCRIT system. Archives of General Psychiatry, 48, 764-770.

Neale, M. C. (1999) Mx: Statistical Modeling (5th edn) Richmond, VA: Department of Psychiatry, Medical College of Virginia.

Peralta, V. \& Cuesta, M. J. (1999) Diagnostic significance of Schneider's first-rank symptoms in schizophrenia. Comparative study between schizophrenic and non-schizophrenic psychotic disorders. British Journal of Psychiatry, 174, 243-248.

Sartorius, N., Jablensky, A., Korten, A., et al (1986) Early manifestations and first-contact incidence of schizophrenia in different cultures. Psychological Medicine, 16, 909-928.

Schneider, K. (1959) Clinical Psychopathology (trans. M.W. Hamilton). New York: Grune and Stratton.

Spitzer, R. L. \& Endicott, J. (1978) Schedule for Affective Disorders and Schizophrenia: Lifetime Version. New York: New York State Psychiatric Institute.

_ , _ \& Robins, E. (1978) Research Diagnostic Criteria for a Selected Group of Functional Disorders. New York: New York State Psychiatric Institute.

World Health Organization (1992) The ICD-I0 Classification of Mental and Behavioural Disorders: Clinical Descriptions and Diagnostic Guidelines. Geneva: WHO. 